The Right Place for Me: A Moderated Mediation Model to Explain Involvement of Employees Aged Over 50 Years

\author{
Prof. Claudia Manzi \\ Catholic University of Milan \\ Dr. Sharon Coen \\ Salford University, Manchestern \\ Dr. Eleonora Crapolicchio \\ University of Modena and Reggio Emilia \\ Letizia Medina \\ Catholic University of Milan \\ Dr. Fabio Paderi \\ Catholic University of Milan
}

Keywords: organizational identity, involvement, perceived organizational support, age-based discrimination

Corresponding author: Claudia Manzi, Department of Psychology, Catholic University of Milan, L.go Gemelli, 1, 20129 Milan, Italy. email: claudia.manzi@unicatt.it, tel: 00390272342686. 


\title{
The Right Place for Me: A Moderated Mediation Model to Explain Involvement of
}

\section{Employees Aged Over 50 Years}

\begin{abstract}
Over the past decades, employment rates of older workers in most Western countries have rapidly increased. Hence, there is a growing interest in identifying the organizational dimensions that might impact the psychosocial adjustment of workers aged over 50 years. This study focuses on perceived organizational support (POS) and identity-related measures (identification and authenticity) as key organizational components for workers at this stage of life. Further, in the relationships discussed, we explore the moderating role of perceived age discrimination. In an ample sample of older workers $(\mathrm{N}=4563$, aged 50-66 years), a moderated mediational model was tested where older workers' involvement was associated to POS. In the model, this relationship was mediated by organizational identification and authenticity, and the association between POS, identity-related measures, and involvement was moderated by age-based discrimination. Results showed that POS is associated with organizational involvement via organizational identification and authenticity and that high level of age discrimination decreased the positive association between POS, organizational identification, authenticity, and involvement.
\end{abstract}

Keywords: organizational identification, involvement, perceived organizational support, agebased discrimination 


\section{The Right Place for Me: A Moderated Mediation Model to Explain Involvement of Employees Aged Over 50 Years}

Over the past decades, many EU countries have reported growth in the employment rates of older workers. Moreover, the European Commission's Joint Employment Report (2019) highlighted the potential to increase these rates further. Indeed, in 2018, the employment rate for older workers aged 55-64 years in the EU stood at 58.7\%, compared with $46.2 \%$ in 2010 (Eurostat, 2019).

Given that it is a relatively new social phenomenon, recent studies have focused specifically on this target of population, exploring what factors foster or hinder workers' performance and attitude within an organization. Indeed, empirical data are needed to provide insight into how targeted interventions can be best designed to benefit this category of workers. In fact, the rapid demographic changes in the labor force constitute a challenge for organizations; in the current economic climate, most of the industrial economies need older employees to remain in the workforce longer both to reduce the strain on the retirement systems and to carry on making financial contributions (Walker, 2007).

The current study aims at contributing to this line of research by exploring the role of perceived organizational support (POS) on workers' identity processes and consequently on involvement to their jobs. Moreover, to better understand the dynamics concerning the specific target population, we explore the role of age-based discrimination in dampening the positive effects of POS on older adults' involvement in a large sample of workers over 50 years old.

\section{POS, Employees' Identity Processes, and Involvement}

Thus, in this study, we focus on a key component of older workers' work life: organizational involvement (Cook \& Wall, 1980). Organizational involvement has been 
defined as psychological absorption in the activities relating to one's role (Buchanan, 1974) and as a high level of effort in the job on behalf of the organization (Porter, Steers, Mowday, \& Boulian, 1974). Organizations are increasingly interested in exploring involvement, especially as it appears to be associated with higher productivity (Lodahl \& Kejnar, 1965; Hall \& Lawler, 1970). Indeed, research suggests that employees involved in their work have higher production levels, are more willing to struggle to achieve their goals, and invest a lot of energy in what they do. In general, the workers who are involved in their work take more initiative in the decision making to give an important contribution to company success and to be recognized and acknowledged.

For this study, POS resulted to be one of the most important determinants of organizational involvement (Meyer, Stanley, Herscovitch, \& Topolnytsky, 2002). POS comprises the trust of the employees that their employer values their contribution and takes care of their well-being (Eisenberger, Huntington, Hutchinson, \& Sowa, 1986). In the past years, a huge amount of research has analyzed POS antecedents and consequences attesting that this dimension is very important in the definition of work outcomes (e.g., Kurtessis et al., 2017).

Two distinct perspectives have emerged in the literature to explain the relation between POS and involvement: a social exchange perspective (Shore, Tetrick, Lynch, \& Barksdale, 2006) that states that POS increases organizational involvement by creating an obligation to care about the organization's welfare and to help it reach its goals (see also Rhoades, Eisenberger, \& Armeli, 2001) ; more recently, an identity perspective suggested that the employee-employer relationship might be better understood in terms of self-definition and not in terms of reciprocity and exchange (e.g., Marique Stinglhamber, Desmette, Caesens, \& De Zanet, 2013). 
With this latest perspective, Armeli, Eisenberger, Fasolo, and Lynch (1998) have proposed that by fulfilling employees' socio-emotional needs (such as esteem, approval, affiliation, meaning, and purpose), POS may contribute to organizational identification defined as the "perception of oneness with or belongingness to an organization where the individual defines him or herself at least partly in terms of their organizational membership" (Mael \& Ashforth, 1992, p. 109). Identification with particular groups is at the basis of our social identities, as postulated by social identity theory (Tajfel, 1968). Because individuals are motivated to maintain or enhance individual needs associated with social identification (Vignoles, Regalia, Manzi, Golledge, \& Scabini, 2006), they tend to identify with groups that better satisfy these needs (Vignoles et al., 2006) and to develop a strong involvement with these groups. In line with this view, several authors have suggested that in meeting socioemotional needs, POS enhances the likelihood of employees' organizational identification (e.g., Eisenberger \& Stinglhamber, 2011; Sluss, Klimchak, \& Holmes, 2008).

Accordingly, several studies have reported a positive relation between POS and organizational identification (e.g., Kurtessis et al., 2017). Moreover, scholars have formulated a mediational hypothesis in that POS should increase the likelihood of employee identification and this would promote greater work involvement (e.g., Fuller, Barnett, Hester, \& Relyea, 2003; Edwards \& Peccei, 2010; Marique et al., 2013). This mediational hypothesis has been empirically tested in several studies, and all findings support it. For example, in a sample of 736 employees from a UK National Health Service Trust, Edwards and Peccei (2010) showed that POS had a positive effect on identification that, in turn, predicted organizational involvement and turnover intention. In two studies, Marique et al. (2012) replicated these findings showing that organizational identification partially mediates the relation between POS and effective commitment. Caesens, Marique, and Stinglhamber (2014) 
analyzed the conjoint role of social exchange and social identification mediational hypothesis in the relation between POS and work commitment. On the basis of two different samples, results indicate that both felt obligation and organizational identification partially mediate the relation between POS and commitment. Moreover, even if not directly focusing on work commitment as the final outcome variable of this mediational hypothesis, findings from studies conducted in different cultural contexts provide evidence in support of this model: in a sample of 238 subordinate-supervisor dyads from the People's Republic of China, Shen et al. (2014) showed that organizational identification partially mediates the relation between POS and other work-related outcomes (e.g., turnover intention and work performance); Lam, Liu, and Loi (2016) collecting longitudinal data from 363 nurses in China also reported that nurses' POS is related to work outcomes and that the relation is mediated by organizational identification. Finally, a meta-analysis on POS antecedents and outcomes provided further support of the mediated effect of POS on in-role performance through organizational identification (Kurtessis et al., 2017).

Building on this well-established mediational model, we propose an extended model. We consider another way through which employee-employer relationship — in a particular POS — may affect employees' self-definition by fostering employees' experience of authenticity.

The construct of authenticity has recently gained attention within the field of organizational studies, and empirical evidence shows that authenticity is a central force in organizations (e.g., van den Bosch \& Taris, 2018) especially for employees, as older workers, who are at risk of stigmatization (Cha et al., 2019).

As evidenced in Cha et al.'s (201() review authenticity in the workplace has been defined and measured differently in the literature. In their review, they find 10 different constructs referred 
to as authenticity. Although there are important differences between these constructs (e.g., some of them considering authenticity as something personally perceived, whereas others consider it something that has to be rated by an external observer), there is a strong overlap among the various conceptualizations in that they mostly refer to the definition of authenticity as an alignment between what is internal or private and what is external or public (Harter, 2002). Here we refer to authenticity as the subjective experience of alignment between one's internal sense of self and external expressions (Caza, Moss, \& Vough, 2018). On the basis of Wood et al. (2008), this definition of employees' authenticity comprise both the extent to which they feel in touch with their true selves when they are in the workplace and the extent to which they behave consistently with their physiological states, emotions, and deep-level cognitions.

For this study, the association between authenticity and involvement has been well documented in the literature (Leroy, Anseel, Dimitrova, \& Sels, 2013; Metin, Taris, Peeters, van Beek, \& van den Bosch, 2016; Reis, Trullen, \& Story, 2016; van den Bosch \& Taris, 2014). In Sutton's (2020) meta-analysis, the positive relationship between authenticity and involvement yields a $r=0.37$. Notably, in Cable et al.'s (2013) experimental study, the impact of authenticity on employees' involvement goes beyond the effect of organizational identification. According to this literature, there are two primary ways in which authentic behavior may enhance work involvement (Cha et al., 2019). First, authentic employees' may count fully on their internal resources (e.g., energy and personal strengths) at work as they do not have emotional and cognitive load dedicated to conceal their true selves (e.g., Hur, Moon, \& Jun, 2013). Second, feeling authentic at work results in internal attributions for one's behavior, which increases one's involvement to the work activities.

As for the relation between organizational climate and authenticity, only few studies 
have analyzed the extent to which the workplace context is conducive to employees' perception of authenticity (Cha et al., 2019). These studies focused on dimensions such as person-organization value incongruence (Hewlin et al., 2017), types of different organizational culture (Riess, Trullen, \& Story, 2014), organizational level of inclusiveness and autonomy granting (Riess, Trullen, \& Story, 2016), and person-environment fit (van den Bosch, Taris, Schaufeli, Peeters, \& Reijseger, 2019). Some of these studies analyzed and tested a possible mediational role of employees' authenticity at work in the relationship between the organizational context and employees' work outcomes. Van den Bosch et al. (2019) showed that the relationship between person-environment fit and several work outcomes is mediated by experienced authenticity. Similarly, Kuntz and Mary Abbott (2017) showed that person-environment fit facets were positively related to involvement through authentic living. Reis, Trullen, and Story (2016) indicated that work environment characterized by high level of inclusiveness and autonomy granting is positively associated with employees behaving more authentically at work, and this in turn predicts positive work outcomes.

In this study, we hypothesize a mediational role of authenticity in the relation between POS and work involvement. Indeed, POS nurtures the employees' sense that their organization values their contributions and cares about their well-being. It fulfills employees' socio-emotional needs of esteem, approval, affiliation, meaning, and purpose (Armeli, Eisenberger, Fasolo, \& Lynch, 1998). In doing so, we postulate that POS creates the basis for a serene and safe working environment where employees can feel at ease in manifesting themselves and where they experience a climate that does not require them to conform to the rules and organizational values to obtain rewards. Interestingly, close to our proposed mediational model, Hur, Moon, and Jun (2013) have shown in a study on employees' of the 
airline industry that POS has a positive effect on deep acting (a dimension that is close to authenticity) and this in turn positively influences organizational involvement.

We thus formulate our first two hypotheses as follows:

Hypothesis 1: Organizational identification will mediate the relation between older workers' POS and organizational involvement.

Hypothesis 2: Authenticity will mediate the relation between older workers' POS and organizational involvement.

In other words, we hypothesize that the perception of a supportive environment fosters on the one hand the extent to which an individual identifies with the organization they work for and on the other the extent to which employees feel able to express their idiosyncrasies and that these identity-related variables can in turn foster employees' involvement in the workplace.

The Moderating Role of Age Discrimination in the Relation Between POS, Identity, and

\section{Involvement}

Previous studies have focused on a series of moderators of the relationship between POS and its outcomes, such as perceived organizational competence (Kim, Eisenberger, \& Baik, 2016) and perceived prestige (Mignonac, Herrbach, \& Guerrero, 2006). Findings of these studies have shown that POS is the work experience most strongly linked to affective organizational commitment when employees report high levels of perceived organizational competence and better organization external image. Given the characteristics of our target population, we analyze here age discrimination as a moderator variable in the relation between POS and the considered outcomes (i.e., organizational identification, authenticity, and work involvement). 
Unfortunately, the above-mentioned increase in older-aged workforce is accompanied with the spread of stereotypes associated with older workers. There is mounting evidence that older workers are victims of prejudice and discriminatory behaviors (Kunze, Boehm, \& Bruch, 2011; Redman \& Snape, 2006; Stypinska \& Turek, 2017).

According to UNECE (Policy Brief on Ageing, 2019), older employees are considered inflexible, frail, incompetent, out of touch, and slow (see also Posthuma \& Campion, 2009). Specifically, they are perceived as having lower ability and being less motivated and less productive than younger workers, having high resistance to change, being harder to train, being less adaptable, having a lower ability to learn, thereby having less potential for development; furthermore, they are seen with a shorter job tenure, meaning that they will provide fewer years in which the employer can reap the benefits of training investments. They cost more because they have higher wages, utilize more benefits, and are closer to retirement. Finally, they are perceived to have deteriorating health and/or cognitive ability and take more sick days.

Because of this negative stereotype, older workers may experience age discrimination, defined as "a process of systematic stereotyping and discrimination against people due to their age" (Butler, 1975). Age discrimination has different effects on the worker; for example, it limits the possibilities of accessing the job market, training courses, and career advancement (Cuomo \& Mapelli, 2014; Lazazzara \& Bombelli, 2011). A small number of studies have demonstrated that age discrimination is able to reduce work commitment, involvement, and job satisfaction (e.g., Bal \& Kooji, 2011, Bayl-Smith \& Griffin, 2014; Manzi et al., 2019). Discrimination has effects not only on the person's working life but also on their psychosocial adjustment and health (Casad \& Bryant, 2016; Von Hippel, Kalokerinos, \& Henry, 2013). Specifically, it is seen as a stressor (Snape \& Redman, 2003) that can elicit states of anxiety 
(Bousfield \& Hutchinson, 2010), depressive symptoms (Han \& Richardson, 2015), and a reduction in personal well-being (Fernandez-Ballesteros, Olmos, Santacreu, Bustillos, \& Molina, 2017).

Overall, these studies have consistently shown the detrimental effect of age discrimination on several work- and health-related outcomes for older workers. To our knowledge, the moderating effect that age discrimination, as well as discrimination in general, has on the relation between positive indicators of organizational climate and worker outcomes has rarely been considered. An exception is Jiang (2015), who demonstrated how the effect of organizational image on organizational identification is stronger when workers perceived a low level of discrimination.

Here, we focus on how age-based discrimination can hinder the positive effects of POS on workers' organizational identification, authenticity, and work involvement.

Even though — to the best of our knowledge - there are no studies investigating the relation between age-based discrimination and POS, empirical findings show that organizational fairness in general makes an important contribution to POS (Rhoades \& Eisenberger, 2002). In the meta-analysis of Kurtessis et al. (2017), fairness perceptions emerged as the strongest predictor of POS. In Jiang (2015), discrimination moderates the relation between support and identification in a sample of temporary agency workers in China. Therefore, we expect here that the combination of POS and fairness (or, in our case, lack of age discrimination) would be particularly beneficial to improve organizational identification, authenticity, and involvement of older workers, whereas high levels of POS if associated with high levels of age discrimination would be less beneficial for the identification process and the older employees' involvement.

Indeed, age-related stereotypes elicit feelings of pity toward older people and lead to 
patronizing and protective paternalism (Swift, Abrams, Lamont, \& Drury, 2017). In general, these beliefs can contribute to views that older people should be helped or protected. Consequently, when older workers perceive that they are being discriminated against on the basis of their age, they may interpret organizational support as a manifestation of protective paternalism rather than a demonstration of interest from their employer. This could affect the positive effect that POS has on organizational identification, authenticity, and involvement because POS does not fulfill the socio-emotional needs of self-esteem, competence, and meaning if interpreted this way. Therefore, we will test the following moderation hypotheses:

Hypothesis $3 a$ : The relation between POS and organizational identification is moderated by age discrimination. Specifically, we expect that high level of age discrimination will decrease the positive effect of POS on organizational identification.

Hypothesis $3 b$ : The relation between POS and authenticity is moderated by age discrimination. Specifically, we expect that high level of age discrimination will decrease the positive effect of POS on organizational identification.

Hypothesis 3c: The relation between POS and organizational involvement is moderated by age discrimination. Specifically, we expect that high level of age discrimination will decrease the positive effect of POS on organizational involvement.

Note that in testing all the hypothesized relations, we controlled for the effect of sociodemographic aspects as possible intervening variables. Within an intersectionality perspective (e.g., Cleverand, Huebner, \& Hanscom, 2017), it has been claimed that diversity categoriesgender, social status, race, sexual orientation, and age - interact on multiple and often simultaneous levels. Hence, research that treats demographic groups (e.g., older individuals) as homogenous may not analyze important implications deriving from other aspects of a 
person's social identity. In particular, in this study, we focused our attention on gender and job status. Scholars from different fields of research have underlined the importance of exploring gender differences when studying aging (e.g., Bennet \& Zaidi, 2016; Murphy \& Cross, 2017). Moreover, studies have also shown the importance of analyzing differences related to job status when studying aging at workplaces (Manzi et al. 2019; von Hippel et al., 2013).

\section{The Social Context of This Study}

In this study, we collected data from an ample sample of Italian workers over 50 years old. Italy is one of the oldest European countries (OECD, 2017) since $37.1 \%$ of its citizens are aged between 40 and 64 years, whereas $19.1 \%$ of citizens are aged between 65 and 84 years, and at least, $3.5 \%$ are aged above 85 years. As in the rest of Europe, the aging population is growing rapidly in Italy, and these demographic changes have a deep impact on the labor market. The number of workers aged above 55 is rising rapidly and has almost doubled in the last 10 years (ISTAT, 2019).

As for age discrimination, data from the Eurobarometer (2015) show that in Italy, older workers' rate of age discrimination is one of the highest in Europe. Nevertheless, studies on the detrimental effect of age discrimination for workers are rare. An exception is Manzi et al. (2019) who conducted a study on the Italian national rail company. The authors have shown that age discrimination has a strong impact on organizational involvement of older workers. This study will extend this finding by exploring one of the mechanisms underpinning the negative impact of age discrimination on performance, i.e., analyzing the detrimental effect that age discrimination may have in the positive relationship between POS, organizational identification, and involvement.

\section{Method}

\section{Data collection and participants}


Data were collected in a telecommunications company, which offers fixed and mobile telephony services, IP telephony, Internet, and cable television in Italy and abroad.

Participants were contacted by email through the Human Resources Offices of the company. The email presented the study and contained a link to an anonymous online survey. The email introduced the study "Talenti senza età" (Ageless Talents), an Italian national who examines the work conditions of older employees across several organizations. The research was founded by Valore D, an association of companies that promotes diversity in the workplace.

The total sample comprises over 4563 employees aged between 50 and 66 years $(\mathrm{M}=54.7, \mathrm{SD}=3.2)$, residents in different areas of Italy, of whom, $67.4 \%$ are men. Participants self-reported employment status through the classification of workers under the Italian labor law (Art. 2095, Codice Civile Italiano), which differentiates levels of job status (usually corresponding to decreasing levels of income and time flexibility). Response options were managers (dirigenti), supervisors (quadri), clerks (impiegati), and manual workers (operai). In our sample, $2.2 \%$ participants were managers, $21.0 \%$ were supervisors, and $76.98 \%$ were clerks.

\section{Measures}

Organizational support. Organizational support was assessed using the three items from Eisenberger, Huntington, Hutchison, and Sowa (1986). Responses were based on a 5-point scale ranging from 1 (totally disagree) to 5 (totally agree). Example items are "My company really cares about my well-being" and "My company shows very little interest in me" (reverse coded; $\alpha=.76)$.

Organizational identification. Organizational identification was measured with the shared experience subscale of Mael and Tetrick's (1992) organization identification scale. Note that it has been shown that this measure is significantly less overlapping with 
involvement than other related measures (Mael \& Tetrick, 1992). Responses were based on a 5-point scale ranging from 1 (totally disagree) to 5 (totally agree). Example items are "I'm very interested in what others think about my organization" and "When I talk about my organization, I usually say 'we' rather than 'they"' $(\alpha=0.86)$.

Authenticity. Authenticity was measured using two subscales of the individual authenticity measure at work (Van den Bosch \& Taris, 2014): Authentic Living and SelfAlienation. Given the high correlation between the two subscales $(>.60)$, we collapsed them into a single high-order scale and calculated items average to compute an authenticity score. Example items are "At work, I always stand by what I believe in" and "I don't feel who I truly am at work" $(\alpha=0.73)$.

Organizational involvement. Organizational involvement was measured with the Organizational Involvement subscale of the Organizational Commitment Scale (Cook \& Wall, 1980) with three items with five options ranging from 1 (strongly disagree) to 5 (strongly agree). Example items are "I'm not willing to put myself out just to help the organization" and "To know that my own work had contributed to the good of the organization would please me" $(\alpha=0.74)$.

Age-based discrimination. Perceived age-based discrimination in the workplace were assessed with von Hippel et al.'s (2013) measure. This 5-item scale was originally developed to measure stereotype threat among African Americans (Aronson \& Steele, 2005) and was subsequently adapted to assess perceived age-related stereotyping in the workplace. Participants responded using a 5-point scale ranging from 1 (strongly disagree) to 5 (strongly agree). Example items are "People of my age often face biased evaluations in this workplace" and "Some of my colleagues feel that I have less ability because of my age" $(\alpha=0.67)$.

Data Analysis and Results 
As organizational identification and organizational involvement have been seen in previous studies as overlapping constructs (Riketta \& van Dick, 2005), we performed a confirmatory factor analysis to verify that they were distinct in the perception of our participants. We performed covariance structure analyses using the AMOS software package. First, we screened the data for univariate and multivariate outlying cases and to check the variable distributions for normality. We then compared the following two models: (a) Oblique two-dimensional model. Factor loadings and error variances were estimated, and the correlation between involvement and organizational identification was also estimated. This model tested the hypothesis that involvement and organizational identification are different constructs. (b) One-dimensional model. In this model, factor loadings and error variances were estimated as in the previous model but with the correlation between involvement and organizational identification fixed at 1 . This model tested the hypothesis that involvement and organizational identification are overlapping constructs. We thus compared goodness of fit indices of these two models through $\Delta \chi^{2}$. The comparison between the two models showed clearly that the oblique model better represents the data: $\Delta \chi^{2}=5072,4 \mathrm{df}=1, \mathrm{p}<0.001$. This suggests that involvement and organizational identification were distinct constructs in the perception of our participants.

We then computed single indicators for POS, organizational identification, authenticity, organizational involvement, and age discrimination by averaging the items on each scale. In analyzing the statistical distribution of the variables for univariate normality, no issues emerged with regard to skewness and kurtosis (Gravetter \& Wallnau, 2014). Table 1 shows means, standard deviations, and correlations between these variables.

Hypothesis 1: Organizational identification mediates the relationship between older workers' POS and organizational involvement. 


\section{Hypothesis 2: Authenticity mediates the relationship between older workers' POS} and organizational involvement.

To test our first and second hypotheses, we performed a path analysis utilizing a single observed score for each construct tested in the model.

Path coefficients were estimated using the maximum likelihood method, and the nonparametric bootstrapping method (based on 2,000 replications) was used to calculate standard error and confidence intervals of indirect effects (Cheung \& Lau, 2008). First, we tested direct and indirect (through authenticity and organizational identification) association between POS and organizational involvement in a just-identified model with 0 degree of freedom (Figure 1). All the estimated paths were significant. Figure 1 shows path coefficients and $R^{2}$ of the proposed model. To evaluate the goodness of fit with our just-identified model, we considered the $\mathrm{R}^{2}$ of each endogenous variable (see also Jöreskog \& Sörbom, 1996). The squared multiple correlation indicates that the model explains a significant portion of organizational involvement variance: $36 \%(95 \%$ CI [33\%, 38\%]).

Tests to examine whether authenticity and organizational identification mediated the relationship between POS and involvement revealed an indirect effect through authenticity $(\beta=0.02,95 \%$ bootstrap CI: $[0.018,0.022])$ and an indirect effect through organizational identification $(\beta=0.13,95 \%$ bootstrap CI: $[0.091,0.170])$. Results of this model confirm our first and second hypotheses: POS is significantly associated with organizational involvement, and this association is partially mediated by organizational identification (H1) and authenticity (H2).

Finally, to control for a possible effect of gender and job status, we tested a model where job status and gender were related to all the variables present in the model. Note that as supervisors were very few in number, we collapsed manager and supervisors into a single 
category. This model did not change significantly the relation already found in the previous model. We found small but significant negative association between job status and POS, authenticity, organizational identification, and organizational involvement, indicating that workers with lower status display lower level of the aforementioned variables. We also found a small and significant negative association between gender and organizational identification, indicating that women have slightly lower levels of identification, and a significant and positive association of gender and authenticity, evincing that women report higher level of authenticity.

Hypothesis 3a: Age discrimination moderates the relationships between POS and organizational identification.

Hypothesis 3b: Age discrimination moderates the relationships between POS and authenticity.

Hypothesis 3c: Age discrimination moderates the relationships between POS and organizational involvement.

To test our second hypothesis, we performed two moderated mediation analysis using MODEL 8 of Hayes' SPSS macro PROCESS (Hayes, 2013). This model tests if the relation between an independent variable $(X)$ affects a dependent variable $(Y)$, if the effect of $X$ on $Y$ is mediated by variable $M$, if the effect of $X$ on $Y$ is moderated by variable $W$, and if the effect of $X$ on $M$ is moderated by variable $W$. Results of the first model where organization identification was the mediator showed that there was a significant moderation of age discrimination in the relationship between POS and organizational identification $(\beta=-0.058$, 95\% bootstrap CI: $[-0.087,-0.028])$ and in the relationships between POS and organizational involvement $(\beta=-0.036,95 \%$ bootstrap CI: $[-0.059,-0.019])$. Specifically, as shown in Figures 2, the direct effect of POS on organizational identification, the direct effect of POS on 
organizational involvement, and indirect effects of POS on organizational involvement were lower at high levels of age discrimination. Adjusted $\mathrm{R}^{2}$ for this model is .343. Finally, we computed a model adding authenticity as a covariate in order to control the effect of this variable. The pattern of results remained unvaried.

Next, we tested if these relationships could vary for the effect of gender and job status. We first performed our previous moderated mediated model with gender and job status as covariates. The effects of mediation or moderation in this model did not vary. We only found a significant effect of gender and job status on organizational identification (gender: $\beta=-0.083$, 95\% bootstrap CI: $[-0.135,-0.030]$; job status: $\beta=-0.149,95 \%$ bootstrap CI: $[-0.206$, $-0.091])$ and a significant effect of job status on organizational involvement $(\beta=-0.080,95 \%$ bootstrap CI: $[-0.126,-0.035])$. These results show that in our sample, men and high-status workers have higher levels of organizational identification and high-status workers show higher organizational involvement. We then tested if gender and job status could affect the moderation effect of age discrimination in the relationship between POS and organizational identification (using MODEL 12 in PROCESS). None of the three interaction terms (gender*age discrimination*POS and job status*age discrimination*POS) was significant attesting that the moderation effect seems to work similarly for men and women and for workers of different job status.

We then tested our second moderation-moderated model where authenticity was the mediator. In this model, age discrimination did not significantly moderate the relationship between POS and authenticity. As in the previous model, we found a significant moderation of age discrimination in the relationship between POS and organizational involvement $(\beta=-0.072,95 \%$ bootstrap CI: $[-0.099,-0.044])$. Adjusted $\mathrm{R}^{2}$ for this model is 0.132 . As for the previous model, we finally controlled for the effect of organizational identification, 
inserting this variable as a covariate of the model. The pattern of results remained unvaried. We then tested if gender and job status could affect the moderation effect of age discrimination in the relationship between POS and organizational identification (using MODEL 12 in PROCESS). None of the three interaction terms (gender*age discrimination*POS and job status*age discrimination*POS) was significant attesting that the moderation effect seems to work similarly for men and women and for workers of different job status.

\section{Discussion}

This article focused on analyzing contextual and individual antecedents of work involvement of older workers as it is very important for modern organizations to have employees aged over 50 years engaged in their jobs. One of the main stereotypes about older workers is their lack of motivation and involvement in their work (Nelson, 2002). For this reason, many multinational companies that have a substantial percentage of workers over 50 years old often decide to invest their resources in support policies aimed at making their workers more involved. Indeed, several studies have shown that most committed workers have higher levels of productivity (Hillman, Nicholson, \& Shropshire, 2008; Kreiner, Hollensbe, \& Sheep, 2006).

We propose a moderated mediational model in which POS predicted involvement and this relationship was mediated by organizational identification and authenticity and in which age-based discrimination moderated these relations.

Our results, confirming the existing literature on this topic (e.g., Kurtessis et al., 2017), show that POS has a positive impact on workers' involvement. The analyses performed also confirm that - in line with a social identity perspective - when older workers feel supported, they tend to identify more with their organization, and this partially explains why they 
increase their levels of involvement. These results replicate findings of existing studies analyzing different cohort of workers and conducted on differing cultural contexts (e.g., Kurtessis et al., 2017).

Going beyond this replication results, our study also provides new insight to understand how the organizational context affects employees' self-processes and how this in turn is associated with employees' involvement. For the first time, we tested an improved mediational model that adds employees' authenticity as mediator of the relationship between POS and involvement. Consistent with what was hypothesized, we found support for our prediction. Results give evidence of a significant mediated effect of POS on involvement through authenticity, controlling for the effect of organizational identification. It seems that working for an organization that is interested in employees' well-being may help workers aged over 50 years to feel more at ease and more in contact with their true selves, in that they do not need to enact instrumental and inauthentic behavior to obtain benefits. The effect size of this extended mediational model is notable (0.36), explaining a significant amount of variance of involvement of employees over 50 years. Thus, companies seem to help their workers by fostering important individual needs that maintain positive identity processes in different ways and in effect increase involvement.

Previous studies have shown that age-based stereotype threats can deter older workers from staying in the workforce or hinder their motivation to work (Edward \& Paccei, 2010; Brooke \& Taylor, 2005; Manzi, et al., 2019). In line with this literature, results also show that age-based discrimination negatively affects these relationships: Perceived discrimination based on age reduces POS's ability to foster involvement both directly and indirectly through organizational identification. Even if the moderation effect is small, this study highlights an issue with the key variables in our sample: Although normally workers would be more 
involved the more that they feel their institution is supportive, this relationship weakens the more they feel that they have been discriminated against based on their age. Certainly, this small improvement should be further analyzed with (quasi)experimental follow-up studies.

With an increasing age diversity in organizations, there is a greater risk of age discrimination because of the negative stereotypes (Kunze, et al., 2011). Our research highlights the need for organizations to take seriously the threat of such discrimination in the workplace if they wish to maintain highly involved workers. Organizations therefore should not only implement general support policies but also focus on the age diversities and on the fight against age stereotypes. A possible way to change age stereotypes is the generation of opportunities for positive intergenerational contact, which has been demonstrated to reduce prejudice and increase in-group identification (Abrams, Eller, \& Bryant, 2006). Such policies may provide increased support and opportunities for older workers, thereby fostering increased levels of work involvement (Flynn, 2010; Xanthopoulou, Bakker, Demerouti, \& Schaufeli, 2009). Moreover, literature suggests that intervention methods highlighting counter-stereotypical and positive examples of a target group hold promise for attitude amelioration (e.g., Ramasubramanian, 2011). For example, Malinen and Johnston (2013) have found that the imagery of a counter-stereotypical older worker reduces the degree of explicit bias against that group. Thus, internal and external companies' communication should work in the direction of avoiding stereotypical presentation of this target population and increase the exposure to counter-stereotypical and positive older workers.

This study presents also some limitations. First of all, the correlational nature of our design does not permit to infer the direction of causality. As far as for the mediation of organizational identification, previous studies have assessed the direction of these relationships (Lam et al., 2016), and thus, we feel that there is enough evidence to at least 
suggest a cycle of influence between POS, organizational identification, and organizational involvement. As far as for authenticity, the direction of the path analyzed is still to be highlighted. Specifically in some studies, it has been proposed that organizational identification could be a predictor of authenticity that in turn predicts work outcomes (Mishra, 2011). Moreover, our study includes only older workers. Future researches should analyze this model confronting different generational cohorts. These would allow to see if these results could vary according to generations of workers. Moreover, it would be interesting to replicate our theoretical model in a sample of younger workers who are, as often as older workers, targets of age-based discriminations (Snape, \& Redman, 2003). Finally, data were collected through self-report measures, and even if they were collected in complete anonymity, the questionnaire was presented in a judgment-free manner; hence, the participants could not be completely immune to participants bias.

Despite of the above limitations, this study offers new insights on the processes that leads toward a higher involvement of older workers at work and gives new vision for organizations to intervene in favor of this particular target of population. 


\section{References}

Abrams, D., Eller, A., \& Bryant, J. (2006). An age apart: the effects of intergenerational contact and stereotype threat on performance and intergroup bias. Psychology and aging, $21,691-702$.

Armeli, S., Eisenberger, R., Fasolo, P., \& Lynch, P. (1998). Perceived organizational support and police performance: The moderating influence of socioemotional needs. Journal of applied psychology, 83, 288-297. doi:10.1037/0021-9010.83.2.288

Bal, P., \& Kooij, D. (2011). The relations between work centrality, psychological contracts, and job attitudes: the influence of age. European Journal of Work and Organizational Psychology, 20, 497-523. doi:10.1080/13594321003669079

Bayl-Smith, P. \& Griffin, B. (2014). Age discrimination in the workplace: identifying as a late-career worker and its relationship with engagement and intended retirement age, Journal of Apllied Social Psychology, 44, 588-599. doi:10.1111/jasp.12251

Bennett, R., \& Zaidi, A. (2016). Ageing and development: Putting gender back on the agenda. International Journal on Ageing in Developing Countries, 1, 5-19. Retrieved from http://eprints.glos.ac.uk/id/eprint/3796

Bousfield, C. \& Hutchison, P. (2010). Contact, anxiety, ad young people's attitudes and behavioral intentions towards the elderly. Educational Gerontology, 36, 451-466. doi:10.1080/03601270903324362

Brooke, L., \& Taylor, P. (2005). Older workers and employment: Managing age relations. Ageing \& Society, 25, 415-429. doi:10.1017/S0144686X05003466

Buchanan, B. (1974). Building organizational commitment: The socialization of managers in work organizations. Administrative science quarterly, 533-546. doi:10.2307/2391809 
Butler R (1975). Why survive? Being old in America. New York: Harper \& Row.

Caesens, G., Marique, G., \& Stinglhamber, F. (2014). The relationship between perceived organizational support and affective commitment. Journal of Personnel Psychology, 13, 167-173. doi:10.1027/1866-5888/a000112

Casad, B., \& Bryant, W. (2016). Addressing stereotype threat is critical to diversity and inclusion in organizational psychology. Frontiers in Psychology, 7, 1-18. doi: 10.3389/fpsyg.2016.00008

Caza, B. B., Moss, S., \& Vough, H. (2018). From synchronizing to harmonizing: The process of authenticating multiple work identities. Administrative Science Quarterly, 63, 703745.

Cha, S. E., Hewlin, P. F., Roberts, L. M., Buckman, B. R., Leroy, H., Steckler, E. L., Ostermeier, K., \& Cooper, D. (2019). Being your true self at work: Integrating the fragmented research on authenticity in organizations. Academy of Management Annals, $13,633-671$.

Cheung, G. W., \& Lau, R. S. (2008). Testing mediation and suppression effects of latent variables: Bootstrapping with structural equation models. Organizational research methods, 11, 296-325.

Cleveland, J. N., Huebner, L. A., \& Hanscom, M. E. (2017). The Intersection of Age and Gender Issues in the Workplace. In Age Diversity in the Workplace: An Organizational Perspective. Emerald Publishing Limited.

Cook, J., \& Wall, T. (1980). New work attitude measures of trust, organizational commitment and personal need non - fulfilment. Journal of Occupational Psychology, 53, 39-52. doi:10.1111/j.2044-8325.1980.tb00005.x 
Cuomo, S., \& Mapelli, A. (2014). Engagement e carriera: il peso dell'età. Milano: EGEA S.p.A.

Edwards, M. R., \& Peccei, R. (2010). Perceived organizational support, organizational identification, and employee outcomes: Testing a simultaneous multifoci model. Journal of Personnel Psychology, 9, 17-26. doi:10.1027/1866-5888/a000007

Eisenberger, R., Huntington, R., Hutchison, S., \& Sowa, D. (1986). Perceived Organizational Support. Journal of Applied Psychology, 71, 500-507. doi:10.1037/0021-9010.71.3.500

Eisenberger, R., \& Stinglhamber, F. (2011). Perceived organizational support: Fostering enthusiatic and productive employees. Washington, DC, US: American Psychological Association. doi:10.1037/12318-000

Eurobarometer on Discrimination (2015). Retrieved from http://ec.europa.eu/justice/events/colloquium-fundamental-rights2015/files/factsheets/factsheet_eurobarometer_fundamental_rights_2015_en.pdf European Commission's Joint Employment Report (2019), retrived from http://ec.europa.eu Eurostat (2019). Employment statistics. retrived from http://ec.europa.eu

Fernandez-Ballesteros, R., Olmos, R., Santacreu, M., Bustillos, A., \& Molina, M. A. (2017). The role of perceived discrimination on active aging. Archives of gerontology and geriatrics, 71, 14-20. doi:10.1016/j.archger.2017.02.004

Flynn, M. (2010). Who would delay retirement? Typologies of older workers. Personnel Review, 39, 308-324. doi:10.1108/13620431011075349

Fuller, J. B., Barnett, T., Hester, K., \& Relyea, C. (2003). A social identity perspective on the relationship between perceived organizational support and organizational commitment. The Journal of Social Psychology, 143, 789-791. doi:10.1080/00224540309600432

Gardner, W. L., Cogliser, C. C., Davis, K. M., \& Dickens, M. P. (2011). Authentic leadership: 
A review of the literature and research agenda. The leadership quarterly, 22, 1120-1145.

Gravetter, F. J., \& Wallnau, L. B. (2014). Introduction to the t statistic. Essentials of statistics for the behavioral sciences, 8, 252.

Hayes, A. F. (2013). Introduction to mediation, moderation, and conditional process analysis: A regression-based approach. New York, NY: Guilford.

Hall, D. T., \& Lawler, E. E. (1970). Job characteristics and pressures and the organizational integration of professionals. Administrative Science Quarterly, 15, 271-281.

Han, J., \& Richardson, V. E., (2015). The relationships among perceived discrimination, selfperceptions of aging, and depressive symptoms: A longitudinal examination of age discrimination. Aging \& Mental Health, 19, 747-755. doi:10.1080/13607863.2014.962007

Harter, S. 2002. Authenticity. In C. R. Snyder \& S. Lopez (Eds.), Handbook of positive psychology (pp. 382-394). London: Oxford University Press.

Hewlin, P. F., Dumas, T. L., \& Burnett, M. F. (2017). To thine own self be true? Facades of conformity, values incongruence, and the moderating impact of leader integrity. Academy of Management Journal, 60, 178-199.

Hillman, A. J., Nicholson, G., \& Shropshire, C. (2008). Directors' multiple identities, identification, and board monitoring and resource provision. Organization Science, 19, 441-456. doi:10.1287/orsc. 1080.0355

Hur, W. M., Won Moon, T., \& Jun, J. K. (2013). The role of perceived organizational support on emotional labor in the airline industry. International Journal of Contemporary Hospitality Management, 25, 105-123.

ISTAT (2019). Indicatori Demografici. Stime per l'anno 2018. Report del 7 febbraio 2019. Roma: Sistema statistico nazionale. Istituto nazionale di statistica. 
Jiang, J. (2015). Workers identification. The moderating effect of perceived employment discrimination. Procedia-Social and Behavioral Sciences, 205, 306-314.

Jöreskog, K. G., \& Sörbom, D. (1996). LISREL 8: User's reference guide. Scientific Software International.

Kim, K. Y., Eisenberger, R., \& Baik, K. (2016). Perceived organizational support and affective organizational commitment: Moderating influence of perceived organizational competence. Journal of Organizational Behavior, 37, 558-583. doi:10.1002/job.2081

Kreiner, G. E., Hollensbe, E. C., \& Sheep, M. L. (2006). Where is the "me" among the "we"? Identity work and the search for optimal balance. Academy of Management Journal, 49, 1031-1057. doi:10.5465/amj.2006.22798186

Kuntz, J. R., \& Abbott, M. (2017). Authenticity at work: A moderated mediation analysis. International Journal of Organizational Analysis, 25, 789-803.

Kunze, F., Boehm, S., \& Bruch, H. (2011). Age diversity, age discrimination climate and performance consequences a cross organizational study. Journal of Organizational Behavior, 32, 264-290. doi:10.1002/job.698

Kurtessis, J. N., Eisenberger, R., Ford, M. T., Buffardi, L. C., Stewart, K. A., \& Adis, C. S. (2017). Perceived organizational support: A meta-analytic evaluation of organizational support theory. Journal of management, 43, 1854-1884.

Lam, L. W., Liu, Y., \& Loi, R. (2016). Looking intra-organizationally for identity cues: Whether perceived organizational support shapes employees' organizational identification. Human Relations, 69, 345-367. doi:10.1177/0018726715584689

Lawler, E. E., \& Hall, D. T. (1970). Relationship of job characteristics to job involvement, satisfaction, and intrinsic motivation. Journal of Applied Psychology, 54, 305-312. doi:10.1037/h0029692 
Lazazzara, A., \& Bombelli, M. (2011). HRM practices for an ageing Italian workforce: the role of training. Journal of European Industrial Training, 35, 808-825. doi:10.1108/03090591111168339

Leroy, H., Anseel, F., Dimitrova, N. G., \& Sels, L. (2013). Mindfulness, authentic functioning, and work engagement: A growth modeling approach. Journal of Vocational Behavior, $82,238-247$.

Lodahl, T. M., \& Kejner, M. (1965). The definition and measurement of job involvement. Journal of Applied Psychology, 49, 24-33. doi:10.1037/h0021692

Mael, F., \& Ashforth, B. E. (1992). Alumni and their alma mater: A partial test of the reformulated model of organizational identification. Journal of Organizational Behavior, 13, 103-123. doi:10.1002/job.4030130202

Mael, F. A., \& Tetrick, L. E. (1992). Identifying organizational identification. Educational and Psychological Measurement, 52, 813-824.

Sanna Malinen \& Lucy Johnston (2013) Workplace Ageism: Discovering Hidden Bias, Experimental Aging Research, 39, 445-465, DOI: 10.1080/0361073X.2013.808111

Manzi, C., Paderi, F., Benet - Martínez, V., \& Coen, S. (2019). Age - based stereotype threat and negative outcomes in the workplace: Exploring the role of identity integration. European Journal of Social Psychology, 49, 705-716. doi:10.1002/ejsp.2533

Marique, G., Stinglhamber, F., Desmette, D., Caesens, G., \& De Zanet, F. (2013). The relationship between perceived organizational support and affective commitment: A social identity perspective. Group \& Organization Management, 38, 68-100.

Metin, U. B., Taris, T. W., Peeters, M. C., van Beek, I., \& Van den Bosch, R. (2016). Authenticity at work-a job-demands resources perspective. Journal of Managerial Psychology, 31, 483-499. 
Meyer, J. P., Stanley, D. J., Herscovitch, L., \& Topolnytsky, L. (2002). Affective, continuance, and normative commitment to the organization: A meta-analysis of antecedents, correlates, and consequences. Journal of vocational behavior, 61, 20-52. doi:10.1006/jvbe.2001.1842

Mignonac, K., Herrbach, O., \& Guerrero, S. (2006). The interactive effects of perceived external prestige and need for organizational identification on turnover intentions. Journal of Vocational Behavior, 69, 477-493. doi:10.1016/j.jvb.2006.05.006

Mishra, S. K. (2011). Exploring the Antecedent and Consequences of Authenticity of Emotional Expression. In What Have We Learned? Ten Years On (pp. 319-339). Emerald Group Publishing Limited.

Murphy, C. \& Cross, C. (2017). Gender, Age and Labour Market Experiences. In Parry E., McCarthy J. (Eds.) The Palgrave Handbook of Age Diversity and Work. Palgrave Macmillan, London

Nelson, T. D. (2011). Ageism: The strange case of prejudice against the older you. In Disability and aging discrimination (pp. 37-47). Springer, New York, NY.

OECD (2017). Preventing Ageing Unequally. Paris: OECD Publishing.

Posthuma, R. \& Campion, M. (2009). Age Stereotypes in the Workplace: Common Stereotypes, Moderators, and Future Research Direction. Journal of Management, 35, 158-188. doi:10.1177/0149206308318617

Porter, L. W., Steers, R. M., Mowday, R. T., \& Boulian, P. V. (1974). Organizational commitment, job satisfaction, and turnover among psychiatric technicians. Journal of applied psychology, 59, 603-609. doi:10.1037/h0037335

Preacher, K. J., \& Hayes, A. F. (2004). SPSS and SAS procedures for estimating indirect effects in simple mediation models. Behavior research methods, instruments, \& 
computers, 36, 717-731. doi:10.3758/BF03206553

Ramasubramanian, S. (2011). The impact of stereotypical versus counterstereotypical media exemplars on racial attitudes, causal attributions, and support for affirmative action. Communication Research, 38(4), 497-516.

Redman, T., \& Snape, E. (2006). The consequences of perceived age discrimination amongst older police officers: Is social support a buffer? British Journal of Management, 17, 167175. doi:10.1111/j.1467-8551.2006.00492.x

Reis, G., Trullen, J., \& Story, J. (2016). Perceived organizational culture and engagement: the mediating role of authenticity. Journal of Managerial Psychology, 31, 1091-1105.

Rhoades, L., \& Eisenberger, R. (2002). Perceived organizational support: a review of the literature. Journal of applied psychology, 87(4), 698-714.

Rhoades, L., Eisenberger, R., \& Armeli, S. (2001). Affective commitment to the organization: the contribution of perceived organizational support. Journal of Applied Psychology, 86, 825-836. doi:10.1037/0021-9010.86.5.825

Riketta, M., \& Van Dick, R. (2005). Foci of attachment in organizations: A meta-analytic comparison of the strength and correlates of workgroup versus organizational identification and commitment. Journal of vocational behavior, 67, 490-510.

Shen, Y., Jackson, T., Ding, C., Yuan, D., Zhao, L., Dou, Y., \& Zhang, Q. (2014). Linking perceived organizational support with employee work outcomes in a Chinese context: Organizational identification as a mediator. European Management Journal, 32, 406412. doi:10.1016/j.emj.2013.08.004

Shore, L. M., Tetrick, L. E., Lynch, P., \& Barksdale, K. (2006). Social and economic exchange: Construct development and validation. Journal of applied social psychology, 36, 837-867. doi:10.1111/j.0021-9029.2006.00046.x 
Sluss, D. M., Klimchak, M., \& Holmes, J. J. (2008). Perceived organizational support as a mediator between relational exchange and organizational identification. Journal of Vocational Behavior, 73, 457-464. doi:10.1016/j.jvb.2008.09.001

Snape, E., \& Redman, T. (2003). Too old or Too young? The Impact of perceived age discrimination. Human Resource Management Journal, 13, 78-89. doi:10.1111/j.17488583.2003.tb00085.x

Stypinska, J., \& Turek, K. (2017). Hard and soft age discrimination: the dual nature of workplace discrimination. European Journal of Ageing, 14, 49-61. doi:10.1007/s10433016-0407-y

Sutton, A. (2020). Living the good life: A meta-analysis of authenticity, well-being and engagement. Personality and Individual Differences, 153, 109645.

Swift, H. J., Abrams, D., Lamont, R. A., \& Drury, L. (2017). The risks of ageism model: How ageism and negative attitudes toward age can be a barrier to active aging. Social Issues and Policy Review, 11, 195-231. doi:10.1111/sipr.12031

Tajfel, H. (1968). Second thoughts about cross-cultural research and international relations. International Journal of Psychology, 3, 213-219. doi:10.1080/00207596808247247 van den Bosch, R., \& Taris, T. W. (2014). Authenticity at work: Development and validation of an individual authenticity measure at work. Journal of Happiness Studies, 15, 1-18. Van den Bosch, R., \& Taris, T. (2018). Authenticity at work: Its relations with worker motivation and well-being. Frontiers in Communication, 3, 21.

Van den Bosch, R., Taris, T. W., Schaufeli, W. B., Peeters, M. C., \& Reijseger, G. (2019). Authenticity at work: a matter of fit?. The Journal of psychology, 153, 247-266.

Van Leeuwen, E., Van Knippenberg, D., \& Ellemers, N. (2003). Continuing and changing group identities: The effects of merging on social identification and ingroup bias. 
Personality and Social Psychology Bulletin, 29, 679-690. doi:

$10.1177 / 0146167203029006001$

UNECE (2019). Policy Brief on Ageing.

Vignoles, V. L., Regalia, C., Manzi, C., Golledge, J., \& Scabini, E. (2006). Beyond selfesteem: influence of multiple motives on identity construction. Journal of personality and social psychology, 90, 308-333. doi:10.1037/0022-3514.90.2.308

Von Hippel, C., Kalokerinos, E. K., \& Henry, J. D. (2013). Stereotype threat among older employees: Relationship with job attitudes and turnover intentions. Psychology and Aging, 28, 17-27. doi: 10.1037/a0029825

Walker, D. M. (2007). Older workers: Some best practices and strategies for engaging and retaining older workers (GAO-07-433T). Washington, DC: U.S. Government Accountability Office.

Wood, A. M., Linley, P. A., Maltby, J., Baliousis, M., \& Joseph, S. (2008). The authentic personality: A theoretical and empirical conceptualization and the development of the Authenticity Scale. Journal of Counseling Psychology, 55, 385.

Xanthopoulou, D., Bakker, A. B., Demerouti, E., \& Schaufeli, W. B. (2009). Reciprocal relationships between job resources, personal resources, and work engagement. Journal of Vocational behavior, 74, 235-244. doi:10.1016/j.jvb.2008.11.003 